\title{
INDÍCIOS DE INTERDIÇÕES AO DISCURSO FEMININO E SUAS FORMAS DE RESISTÊNCIA: A REVISTA CARETA E A VONTADE DE VERDADE (1914-1918)
}

\author{
Fernanda Conceição Costa Frazão* \\ lattes.cnpq.br/6019832966814694
}

\begin{abstract}
Resumo: Ao longo do século XX, as mulheres conquistaram novos espaços nas relações sociopolíticas. Eram marcantes as restrições à atuação sócio política feminina, que se pautavam em uma sociedade de padrões patriarcais, que julgava o sexo feminino inferior nas relações humanas. Este trabalho apresenta enunciados da revista de variedades Careta, fonte para delimitar os exercícios de poder históricos através da circulação de enunciados que serviam tanto à informação quanto à instrução da sociedade de um modo geral. Para as mulheres, orientações de comportamento e a expressão de opiniões sobre a atualidade efervescente e diversa, como forma de conformá-las ao destino de recato ou por vezes sugerindo ironia em observar as disparidades entre masculino e feminino. Em contraponto às determinações de um lugar de recato, destaca-se também indícios de resistência feminina aos saberes e poderes que oprimiam e naturalizavam um lugar de silêncio para elas. O movimento dos acontecimentos históricos sugere margens habitadas por possibilidades latentes de respostas à ordem vigente. O movimento sufragista, a Primeira Guerra, a Escola Normal, com ou sem teor de movimento pelos direitos femininos são apresentados como meios de propor o debate sobre a tensão estabelecida no jogo de forças e poder entre o masculino e o feminino.
\end{abstract}

Palavras-chave: História da educação feminina; Revista Careta; Jogos de força e poder.

\section{INDICATIONS OF INTERDITIONS TO THE FEMININE SPEECH AND ITS FORMS OF RESISTANCE: THE CARETA MAGAZINE AND THE WILL OF TRUTH (1914-1918)}

\begin{abstract}
Throughout the 20th century, women gained new spaces in socio-political relations. There were striking restrictions on the socio-political feminine performance, which were based on a society of patriarchal standards, which judged the female sex inferior in human relations. This paper presents statements from the variety ma-

\footnotetext{
* Doutoranda em Educação pela Universidade Federal do Paraná, UFPR (Brasil). Contato:nandac75@gmail.com.
} 
gazine Careta, a source for delimiting historical power exercises through the circulation of statements that served both information and instruction of society in general. For women, behavioral guidelines and the expression of opinions on the effervescent and diverse present, as a way to conform them to the destiny of modesty or sometimes suggesting irony in observing the disparities between masculine and feminine. In contrast to the determinations of a place of modesty, there are also signs of female resistance to the knowledge and powers that oppressed and naturalized a place of silence for them. The movement of historical events suggests margins inhabited by latent possibilities of responses to the prevailing order. The suffragist movement, the First War, the Normal School, with or without the content of the feminine rights movement, are presented as a means of proposing the debate on the tension established in the game of strength and power between the masculine and the feminine.

Keywords: History of female education; Magazine Careta; Game of strength and power.

$$
* * *
$$

\section{O poder institucional e a tentativa de silenciamento feminino}

O poder institucional pode ser percebido em algumas normas e prescrições que estão presentes em nosso cotidiano. Neste trabalho será apresentada a perspectiva do poder institucional sobre as questões de gênero, numa abordagem histórica realizada a partir da revista de variedades Careta (1908-1960, Rio de Janeiro). Para tanto, delimita-se neste texto o que algumas instituições faziam circular em termos de saberes, autorizações e interdições à participação sociopolítica feminina, no recorte temporal de 1914 a 1918. São destacadas também algumas formas de resistência ao padrão estabelecido, como forma de demonstrar a circulação horizontal do poder, que não democrática, mas com possibilidade de respostas diferentes aos padrões estabelecidos.

Ao abordar a relação entre instituições e gênero feminino na segunda década do 1900, numa perspectiva foucaultiana, considera-se as zonas de silêncio a que as mulheres estavam submetidas (ALBUQUERQUE JR., 2007). Do ponto da política nacional faz-se referência ao go- 
verno do presidente Wencesláo Braz (1914-1918): seu silêncio se manifesta na exclusão do direito ao voto e de participação em instâncias da esfera pública/política brasileira. Pode-se falar também de seu silêncio acadêmico, pelo pequeno ingresso em cursos superiores no período, que as excluíam de participar dos discursos médico e jurídico institucionalizados, por exemplo.

Considerando a Primeira Guerra Mundial (1914-1918) como uma instituição, também pode se considerar o silêncio delas, na medida em que a participação feminina não se mostra efetiva na sua organização, que é política. Numa contrapartida dessa relação, uma questão é o que esse momento sugere para a história da educação das mulheres, numa perspectiva mundial. Com os homens dos países envolvidos partindo para o conflito, e na medida em que novos aliados se juntavam ao combate, as funções ditas masculinas precisariam ser ocupadas por quem não partia. Em que medida a Primeira Guerra Mundial afetou o lugar das mulheres na sociedade, segundo o que propõe a Careta? De um modo geral, diante do grande conflito, seria possível permanecer no "mesmo lugar", com os mesmos valores e atitudes para o feminino? Com este suposto deslocamento de funções femininas, é possível afirmar um movimento mundial de influências para as mulheres.

Pensar a atuação sociopolítica feminina ou a sua interdição requer considerar poderes em circulação no momento para o qual se volta o olhar. Para esta análise é adotada a ótica proposta por Foucault (2010a), das relações e jogos de força, do estabelecimento de saberes para a coerção necessária ao que eventualmente se instituía como vontade de verdade.

O poder se estabelece nas relações de forma difusa, constante e horizontal, distribuído por todos os corpos, sem exceção, porém, não democraticamente, posto que é destituído de equidade. Isso promove relações em que há sobreposições, mas nunca a anulação de forças: antes se pode atentar para o controle delas, a sua otimização com vistas a produzir sujeitos normalizados e adequados para situações em que se pretende uma homogeneização dos comportamentos. Dispositivos para coerção através de saberes de forma dissimulada, ou vontade de verdade. 
O que acontece é que, por se tratar de um jogo de forças, dinâmico e horizontal, que não exclui ninguém, o poder pode gerar tanto a conformação quanto a recusa à forma proposta, em maior ou menor escala que, conforme dito, não é democrático, mas identificado como positivo na medida em que produz resultados, seja o corpo dócil ou a resistência (FOUCAULT, 2010b).

O que a resistência extrai do velho homem são as forças, como dizia Nietzsche, de uma vida mais rica em possibilidades. $\mathrm{O}$ super-homem nunca quis dizer outra coisa: é dentro do próprio homem que é preciso libertar a vida, pois o próprio homem é uma maneira de aprisioná-la. A vida se torna resistência ao poder quando o poder toma como objeto a vida. (DELEUZE, 1988, p. 99).

Analisado sob a condição de manifestações concretas, o poder se apresenta no nível do incorpóreo: posto que não tem forma, assume os corpos e ações numa dinâmica que confere a ele uma materialidade nunca definitiva, porém constante (FOUCAULT, 2010a). Tomando esse incorpóreo como o discurso, a revista Careta circulava saberes produzidos por instituições como a medicina, a religião, o Estado, para conformação feminina a papéis estabelecidos como lugares de verdade, de credibilidade, regulando as forças do feminino para direcioná-las e aumentá-las no propósito das formas de comportamento desejadas. Pela coerção, o "discurso verdadeiro" se afirmava porque fundamentado em saberes institucionais.

Assim, papéis femininos eram desempenhados e difundidos, mas na medida em que se pautava em possíveis sobreposições de força, podia gerar a resistência à ordem posta. Por exemplo: conforme se estabelecia o casamento - a união conjugal nos padrões específicos da sociedade do começo do século XX, - como uma prática social naturalizada e regulamentada basicamente pela religião e pela medicina, mesmo assim as possibilidades não se restringiam à submissão. Por vezes, casamentos podiam tomar rumos como o adultério ou o divórcio. A fuga antes dele, também consistia numa alternativa. Tornar-se artista podia ser uma escolha neste sentido, já que à época implicaria na opção entre um marido ou a 
profissão, para a qual haveria de se levar em conta as consequências do discurso moral pejorativo sobre a atividade.

Mas o que parecia prevalecer é a coerção, favorecida pelo conjunto de discursos e práticas que direcionavam as mulheres para esse destino. A própria limitação no acesso e avanço nos níveis de escolarização acabava tornando as mulheres mais subordinadas aos homens. Com isso, a negação do espaço público e político a elas, que acabava por restringi-las aos cuidados com a casa, os filhos e marido.

Como este texto se propõe à análise pela diferença, pelas zonas de silêncio e reações a ele, que geravam o deslocamento da situação feminina, buscaram-se também indícios de comportamentos avessos ao que as instituições e suas verdades propagavam. Assim, a "passividade histórica feminina" ganha a formulação de resistência aos padrões: no período a que este estudo se refere, as mulheres não votavam, porém a aceitação a essa lei era questionada pelo movimento, ainda que pequeno e rechaçado, para o sufrágio feminino, o que acabou por se tornar, quase duas décadas depois, um direito delas. Cabe ainda ressaltar, para este caso, sobre os jogos de força que demarcam extremidades diferentes, que se relacionam a partir do embate de forças. À medida que existia a proibição ao voto feminino, as sufragistas o requeriam e, ao protesto delas, a instituição política respondia com recusa, a imprensa com escárnio, o que não impediu o movimento pelo voto feminino de continuar, nem as instituições de se oporem. Jogo de força e poder.

É no ponto do sistema de exclusão dos discursos-saberes, - que, se exclui algum, inclui ou permite a permanência a outro - que interessa discutir a apresentação e circulação dos saberes em discursos para a educação feminina na Careta. "Sabe-se bem que não se tem o direito de dizer tudo, que não se pode falar de tudo em qualquer circunstância, que qualquer um, enfim, não pode falar de qualquer coisa” (FOUCAULT, 2010a, p. 9). Dessa forma, ainda sem uma participação efetiva das mulheres na escolarização no período, é possível encontrar diversas esferas sociais e instituições que se preocupavam com os papéis femininos, principalmente no que diz respeito à sua atuação na família e possíveis permissões sociais a elas concedidas. Dentre essas instituições que deliberavam sobre 
os modos de ser das mulheres estavam a medicina e a imprensa, que se dedicavam "na formulação de uma série de propostas que visavam 'educar' a mulher para o seu papel de guardiã do lar e da família” (D’INCAO, 1997, p. 230).

A propagação de costumes e práticas considerados próprios para as mulheres passava por instâncias várias e difusas, para o que, cabe pensar: conforme a medicina propunha medidas necessárias à saúde das mulheres, o Estado as reforçava e as divulgava como forma de cumprimento do seu dever de cuidado com a população. Como produção de "efeito de verdade" - num exemplo que toma a medicina como instituição reguladora de algum discurso, - as prescrições chegavam por vezes por meio da imprensa à população, que as absorvia e se encarregavam de uma nova disseminação dos saberes, estabelecendo também o que era próprio das relações diminutas do cotidiano e das ações particulares.

Na História da Sexualidade - Vontade de saber, Foucault analisa as formas de interdição da sexualidade ao longo dos últimos séculos, e faz pensar numa analogia à configuração histórica para as mulheres no período aqui analisado:

O que não é regulado para a geração ou por ela transfigurado não possui eira, nem beira, nem lei. Nem verbo também. É ao mesmo tempo expulso, negado e reduzido ao silêncio. Não somente não existe, como não deve existir e à menor manifestação fá-lo-ão desaparecer - sejam atos ou palavras.(...) Isso seria próprio da repressão e é o que a distingue das interdições mantidas pela simples lei penal: a repressão funciona, decerto, como condenação ao desaparecimento, mas também como injunção ao silêncio, afirmação de inexistência e, consequentemente constatação de que, em tudo isso, não há nada para dizer nem para ver, nem para saber. (FOUCAULT, 1988, p. 10).

A partir dessas ponderações sobre a história da sexualidade, é possível pensar na dimensão histórica do silêncio feminino, como equivalente a uma negação das mulheres no acesso à produção do discurso político, na forma como eram "classificadas, obrigadas a tarefas, destinadas a uma maneira de viver ou a uma certa maneira de morrer, em função de discursos verdadeiros que trazem consigo efeitos específicos de poder" (FOUCAULT, 2005, p. 29). Assim, o que importa aqui são os efeitos de 
verdade aplicados àquela sociedade e sua manifestação no modo de vida das mulheres, que experimentavam a repressão através do silêncio institucional, como uma condição pré-estabelecida para elas.

\section{Interdição à participação política feminina}

A condição de silêncio das mulheres diante do quadro político brasileiro, nas primeiras décadas do 1900, sugere questões sobre as implicações educacionais para elas. Enquanto para o homem "exigia-se para a cidadania política uma qualidade que só o direito social da educação poderia fornecer" (CARVALHO, 1987, p. 45), para as mulheres, nem isso seria suficiente, posto que mesmo alfabetizadas ou até se atingissem graus mais elevados do ensino, ainda assim, não votavam.

É importante propor uma reflexão que considere o processo eleitoral como uma prática recente ou pouco estruturada para o começo do século XX no Brasil, o que não faz naturalizar a intransigência contida na prática das mulheres em não serem admitidas como eleitoras na Constituição da República Brasileira de 1889.

Na tentativa de reverter a situação, o movimento pelo sufrágio feminino acontecia no Brasil e no mundo todo, e parecia ganhar cada vez mais impulso, como na "República Argentina [em que] a Câmara dos Deputados de Santa Fé concedeu às mulheres o direito de voto. Santa fé da Câmara!" (CARETA, 04/o7/1914, p. 26). E assim, entre deboches, apoio ou simplesmente aceitação de um processo que se despontava como irreversível, a Careta cumpria seu papel de informar sobre o desenrolar dos acontecimentos, conforme sufragistas e adeptos tomavam partido pela causa.

No ano de 1917, o Deputado brasileiro Mauricio de Lacerda apresentou o derrotado projeto de lei que propunha conferir às mulheres o livre exercício do direito ao voto (CARETA, 23/o6/1917, p. 29). Com isso, percebe-se que a resistência ao sufrágio feminino não era só uma carica- 
tura da Careta, mas uma recusa do próprio Estado, cujos governos eram compostos até então exclusivamente pelos homens!

$\mathrm{O}$ valor à presença sociopolítica feminina continuava então restrita ao seu aspecto físico, sua beleza. E assim foi apresentada a atuação de uma "revolucionária" pela revista:

O prestigio feminino, por mais esforços que as mulheres façam em defesa dos direitos equivalentes aos dos homens para o seu sexo, hão de ser sempre o que foram e são, destacando-se entre ellas mesmo quando pregam as suas ideias, não as que produzem os melhores argumentos ou que improvisem as mais lindas phrases, mas as que tenham os corpos mais perfeitos e a belleza mais notada... Belém de Sarraga, aquella terrível revolucionária que andou pelo Brasil... era um sucesso... quando subia à tribuna popular, procurava com habilidade collocar-se de maneira que o seu lindo par de roliças pernas ficasse em plena exposição sobre a tribuna. (CARETA, 04/08/1917, p. 20).

Fica claro que discursos de exclusão à participação sociopolítica das mulheres eram circulados de forma naturalizada, como se a sociedade tivesse uma estrutura eterna e imutável: mulheres hão de ser sempre o que foram e são. $\mathrm{O}$ argumento relativo à falta de credibilidade em relação às ideias produzidas por mulheres revela a intransigência dos conceitos produzidos pelo discurso dito patriarcal, que mais interessado numa relação de gênero que lhe garantisse maior dominação, permanecia atento e vigilante ao corpo feminino. A este, espreitado para admiração e controle, não era favorecido uma circulação suficiente para a afirmação do seu contrário. O discurso dominante ainda provocava leituras sociais insuficientes para uma relação harmoniosa entre masculino e feminino.

É curioso ainda perceber como a Careta tratava a possibilidade de as mulheres virem a participar da vida política, ainda que em situações fictícias, emitidas a partir do caráter caricatural e cômico do periódico.

Uma das previsões sobre o futuro das mulheres na política apresentada na Careta faz pensar no escracho das relações que a revista propunha. De título "Um marido futuroso - em pleno regimen do feminismo" (CARETA, 21/07/1917, p. 31), a história trata da previsão do comportamento de um marido no ano de 1940, "alguns annos depois de ter passado no congresso o projecto Mauricio de Lacerda sobre o voto das mulhe- 
res”. Thomaz Bocó, o tal marido, cometera suicídio, tendo sido esmagado por um trem de ferro. Ele trazia um bilhete no bolso, encontrado pela polícia, no qual narrava como havia se envolvido com Anna Bellona, a esposa, a qual conhecera numa reunião eleitoral, em que ela acusava uma concorrente de "se occupar em excesso com os trabalhos de sua casa, em vez de deixa-los para o marido", já sugerindo pautas femininas restritas ao lar.

Ele contou ainda no bilhete sobre os êxitos da carreira política de Anna Bellona, e que, apaixonados, pretenderam se casar: "[Ela] veiu à casa de meus paes para pedir minha mão. Eu, apezar dos 28 annos fiquei vermelho como um pimentão e escondi a cabeça no cóllo de minha mãe”. Casados, após a lua de mel, veio um filho, com o qual ele teve de fugir de uma epidemia, levando-o para Petrópolis. A mulher permaneceu no Rio de Janeiro para cuidar do trabalho na Câmara dos Deputados. Trocando correspondências sobre os cuidados com o filho, Thomaz Bocó disse ser necessário uma ama para amamentar a criança. "Nada de amas. Experimente primeiro amamental-o você mesmo". A história é ilustrada com a cena trágica do marido tentando amamentar a criança no jardim da cidade e a notícia de que a mulher almejava o Senado. O restante do bilhete se tornou ilegível no acidente em que Bocó morreu, de modo que não apresentou mais desfecho (CARETA, 21/o7/1917, p. 31).

É sugestivo, primeiramente, o modo como a Careta propõe uma reversão dos valores, ao insinuar que uma vez com acesso ao poder, as mulheres agiriam de forma intransigente com os homens, narrando ai uma projeção feita como contraponto do tratamento dispensado às mulheres, de as "impedirem" ao acesso às decisões políticas. Numa leitura que incita a divisão de papéis sociais entre o masculino e o feminino, é sugestivo pensar que a Careta simplesmente dizia do fracasso masculino no cuidado com a prole, sendo esta tarefa naturalmente feminina.

Numa outra leitura, pode haver uma ironia no texto da Careta, sobre o lugar dispensado para as mulheres naquele momento: uma opressão que se exercia na sobreposição de atuações sociais, como se a relação entre gêneros não pudesse ser harmoniosa. A interpretação de denúncia para a situação das mulheres, de seu silêncio e submissão social e políti- 
ca, talvez não fosse clara para aquele momento, em que certamente se queria fazer graça, mas independentemente disto, fica evidente uma situação de relação de forças em que uma das partes não seria satisfeita. $\mathrm{Na}$ ficção, a violência sofrida pelo marido Bocó não foi suportada. Por que, então, haveriam de suportá-la as mulheres, com todo aquele quadro de submissão que se entendia como naturalizado para elas? Considera-se o poder político, da forma como era exercido, como opressão para as mulheres por não conceder igualdade de condições para atuação de ambos os sexos, sendo que regulamentações para elas estavam em jogo também.

Ainda neste aspecto, numa referência de efeito caricatural, as bruxas como figuras do imaginário popular foram abordadas com referência às sufragistas. Em texto da seção "Visões da Épocha", assinada por Garcia Margiocco, o autor divaga - num texto por vezes confuso na escritasobre questões espirituais e religiosas para falar de sua crença nas bruxas, e termina por afirmar que elas estavam personificadas nas sufragistas. Ao final, a crítica é em relação ao movimento pelos direitos eleitorais femininos.

(...) É de esperar que a maioria das mulheres, elegidas pelos homens ao throno sentimental da graça e da belleza, recusem agora abandonar as ineffaveis harmonias do lar para irem se entregar aos rudes encargos do homem na praça publica. (...) constatei comtudo a existência das bruxas (...) Não duvido que as infelizes bruxas, exoneradas da direção das lendas de feitiçarias, não tivessem entrada no céu e fossem também expulsas do próprio inferno. O que afirmo, benzendo-me é verdade, é que ellas estão agora sobre a terra e serão ellas que pela recusa das mulheres novas e bellas, encarregar-se-ão de desempenhar no mundo o duplo papel de homem e mulher... visto não terem sexo... As directoras dessa diabólica legião, representadas por três velhas muito feias ${ }^{1}$, estiveram em tempo no Congresso Federal tratando da sua incorporação ao sexo forte... chamem-n'as pois de SUFFRAGISTAS ou lobis-homem quem assim o entender. Ellas serão sempre, emquanto houver um moço que renda prei-

\footnotetext{
${ }^{1}$ A respeito das sufragistas em questão, não há nomes nem informações sobre a situação mencionada, da visita de sufragistas ao Congresso. Porém, a revista menciona constantemente Bertha Lutz e Deolinda Daltro como figuras do sufrágio. Barbara Salesia poderia ser um terceiro nome, já que aparece numa das pequenas narrativas da Careta, em que ela é descrita como quem andava pregando os direitos da mulher (CARETA, 07/04/1917, p. 10).
} 
tos ao gentil sexo a que ellas pertenceram, as verdadeiras bruxas sobre a terra desligadas do convívio ideal dos salões para a tranqüilidade das mulheres bonitas. (CARETA, 20/01/1917, p. 8 , grifo do autor).

Ainda que considerado o tom satírico e humorístico da Careta, o texto revela falta de argumentos mais plausíveis em seu discurso contrário ao sufrágio feminino. Talvez a questão de atribuir às sufragistas a imagem das bruxas partisse dessa falta de justificativas coerentes à negação do direito político. A ideia não se sustentava pelo pretexto vulgar da beleza feminina; e certamente falar em uma negação da pertença do ato de votar ao sexo feminino revela uma generalização bastante tendenciosa e, pode se dizer agressiva ao lugar social das mulheres que se sentissem no direito de exercer o sufrágio.

De tal modo algumas concepções se enraízam no discurso de uma época, como a atribuição de direitos políticos somente ao gênero masculino, que o autor encontrou na Careta a licença para atribuir às mulheres sufragistas o não pertencimento ao próprio gênero feminino, num não lugar, inclassificáveis, como se pode pensar quando o autor as compara às bruxas, sem entrada no céu e também expulsas do inferno²

\section{A possibilidade de acesso ao discurso pela educação}

Pensar nas interdições ou zonas de silêncio à participação político social feminina traz indícios para elaborações sobre a educação das mulheres no período. Fundamentada em "saberes" diversos, que pregavam basicamente a inferioridade intelectual delas e, portanto, um papel social restrito aos cuidados com filhos, casa e a própria beleza, o direito à educação superior praticamente não existia para as mulheres. A Careta em seu contexto parecia ignorar essa possibilidade, já que nem a mencionava. Não se pretende generalizar a pouca entrada das mulheres no ensino

\footnotetext{
${ }^{2}$ Segundo a tradição católica, esse não lugar, nem inferno nem o céu, é chamado limbo.
} 
superior como não existente, mas sim como uma presença não notada através das publicações da Careta, que por vezes divulgava as fotos das turmas de ensino superior no Brasil, não sendo mencionadas mulheres. Assim, conclui-se que a participação delas nesse segmento da educação era irrisória.

É importante que fique claro o teor da analogia entre silêncio feminino na política e o mencionado para a educação, no caso do ensino superior. Recorrendo mais uma vez à institucionalização do discurso político, baseado em grande escala na medicina e no direito, percebe-se uma negação das mulheres desde a possibilidade de entrada delas no que poderia lhes proporcionar um acesso ao discurso autorizado.

O que é afinal um sistema de ensino senão uma ritualização da palavra; senão uma qualificação e uma fixação dos papéis para os sujeitos que falam; senão a constituição de um grupo doutrinário ao menos difuso; senão uma distribuição e uma apropriação do discurso com seus poderes e seus saberes? (...) Não constituiriam o sistema judiciário, o sistema institucional da medicina, eles também, sob certos aspectos, ao menos, tais sistemas de sujeição do discurso? (FOUCAULT, 2010a, p. 44-45).

A regulamentação para o discurso político do ponto do direito e da medicina, proposta por Foucault, ajuda nessa leitura de exclusão das mulheres do aparelho político, na medida em que aponta a educação como a ritualização da palavra, como que sinalizando a permissão para integrar o discurso. Desse modo, não restava às mulheres muitas opções de atuação social, senão aquelas em que a elas era destinado o papel de redistribuir um discurso já formulado, possível apenas de ser transformado no nível da prática, sem possibilidade de interferência nos saberes que o constituía. Restava o questionamento e a resistência aos papéis impostos, o que não era unânime, visto o arranjo coercitivo das instituições.

Portanto, entende-se que o caminho percorrido pelas mulheres foi o das "margens", na medida em que não foram oferecidas a elas a possibilidades de embate político nas primeiras décadas do século XX, nem pela permissão ao voto, nem pela entrada na educação, nos cursos que moldavam o discurso dominante. Entende-se por margens a leitura relacionada à ocasião, oportunidade. 
A este respeito, pode-se pensar em permissões como em relação às artes, atuação admitida para as mulheres, no caso da literatura e da música - que circulariam conforme atendessem aos critérios dos padrões institucionais - e também a atuação delas nas artes cênicas, ainda que com restrições e valor pejorativo, como em relação às atrizes; no exercício do magistério, para o qual a mulher foi recrutada para o ensino primário, na empreitada pela escolarização em combate ao analfabetismo; na necessidade de ocupação de novos papéis, impostos pela Guerra.

\section{O escândalo da Escola Normal: indícios de resistência feminina}

A respeito do conceito de resistência, do ponto da circulação do poder e do seu efeito positivo, o poder não somente cerceia, não tem exatamente uma conotação negativa, de prejuízo para os indivíduos. Ele é positivo na medida em que permite atuações e contra-poder.

Consideremos o que se poderia chamar de localização do poder: quem o detém ou o possui? Ao contrário do que se tende a imaginar a esse respeito, o poder não se restringe a uma forma de dominação maciça; ao analisar esse conceito foucaultiano, fica claro que ele não se concentra como uma barreira vertical nas relações, seu exercício não pode ser considerado como "privilégio" de alguns. Antes, ele é "uma coisa que circula, ou melhor, como uma coisa que só funciona em cadeia. Jamais ele está localizado aqui ou ali, jamais está entre as mãos de alguns, jamais é apossado como uma riqueza ou um bem" (FOUCAULT, 2005, p.35, grifo meu). A afirmação de que o poder transita pelos indivíduos, não se aplica a eles, ganha maior significado se levado em conta a direção - da direção vetorial propriamente dita - das forças que ai atuam, num movimento horizontal: o poder e suas determinações não estão cravadas verticalmente, mas estão em movimento nos indivíduos, e na medida em que já o constituiu, não justifica aplicar-se a ele, mas sim desdobrar através dele essa rede de dominação num nível cada vez mais generalizado e micro, em que os indivíduos são feitos seus intermediários. 
Para fazer pensar numa relação da proposição feita acima e a situação das mulheres abordada neste trabalho, um acontecido curioso para o período tem menção na Careta.

Trata-se, inicialmente, de uma charge publicada na edição do dia19 de junho de 1915, referente à aceitação da Escola Normal enquanto instituição de formação quase exclusivamente feminina. Nela se vê uma moça sentada num banco, recolhida em um dos cantos a ocupar menos de um terço do seu espaço em concorrência com o pai. Sem fala atribuída a ela, recebe conselhos do pai, que com cara de indignação, braços abertos como a pedir retratação lhe dirige: “- Sim, sim. Vocês, até certo ponto, têm razão. Mas é preciso um pouco mais de submissão para que não se diga, mais tarde, que vocês são moças de escól anormal" (CARETA, 19/06/1915, p. 26). É importante ressaltar o jogo de palavras típico da Careta, o trocadilho feito na charge - escol anormal - e que neste caso faz referência a um conceito de classificação médica de cunho psiquiátrico, anormal, que aborda o que está fora da normalidade dos padrões de sanidade. Acima da charge, em texto de Ignacio Costa, faz comentário a respeito de "uma greve, uma revolução na Escola Normal, quasi frequentada exclusivamente por moças", ao que completa "como é que elas se zangaram com o governo e seus superiores?” (CARETA, 19/o6/1915, p. 26).

O texto da Careta não dá informações sobre o que aconteceu de fato na Escola Normal, apenas fala em greve, revolução das normalistas, e dá um viés político ao problema ao mencionar as sufragistas, numa relação "indireta" ao caso: "Não há nenhuma relação entre a revolução da Escola Normal e os motins das sufragistas; mas uma coisa puxa a outra" (CARETA, 19/06/1915, p. 26).

Investigado o caso, levantou-se o que teria sido a sua causa. O jornal $A$ Gazeta, em circulação no período na cidade de São Paulo, publicou notas a respeito do acontecido. Acrescentaram-se as informações de que o ocorrido teria sido em conseqüência de protestos de algumas das normalistas. "O Sr. Alvaro Rodrigues, secretário do prefeito, declarou que a Escola possue actualmente mil e quinhentas alumnas, e destas somente trezentas tomaram parte nas ocorrências dos últimos dias" ( $A$ GAZETA, 
14/06/1915, p. 02). Embora o texto pareça menosprezar o movimento, há que se levar em conta que foram $20 \%$ das alunas adeptas da causa, num contexto avesso à tal reivindicação!

Quanto ao motivo da greve, o diretor da instituição declarou que tudo começou com a falta de quatro professores na Escola Normal, em que algumas alunas ficaram em conversas pelos corredores, e não atendeu à repreensão da inspetora da instituição.

O diretor [Sr. Hans] afirma não ter tocado na moça, que somente foi suspensa por tres dias como castigo de grave desobediência. A inspetora mandou-a retirar-se e quando a alumna ia deixar a sala, começaram os protestos. O Sr. Hans insistiu no pedido de demissão que fizera, mas o Sr. Rivadávia Correia, prefeito do Distrito Federal não o atendeu. Há sérias divergências entre o director e os professores da Escola (A GAZETA, 14/06/1915, p. 6).

O caso parece ter tido repercussão relativa. No periódico já citado, A Gazeta, por duas edições foram publicadas fotos com o mesmo título: "O escândalo da Escola Normal do Rio de Janeiro". Uma delas traz "Um grupo de alumnas sahindo daquelle estabelecimento, depois da ordem de seu fechamento hontem à tarde" (A GAZETA, 15/o6/1915, p. 6), e em outra mostra "Um aspecto da manifestação dos estudantes solidários com as normalistas" ( $A$ GAZETA, 16/06/1915, p. 8).

Não é necessário remeter à questão da rigidez nos processos escolares do início do século XX, que poderia mesmo ser uma prática comum, independente de tratar-se de um público feminino ou não. O que chama a atenção é o cuidado em tratar de uma "revolução fomentada por moças", ressaltando que a elas não cabia o direito de protestar, associando o fato ao recolhimento e obediência necessários a elas.

É interessante ainda ressaltar a postura da revista Careta diante daqueles acontecimentos, sobre os quais não emitiu maiores considerações, além de sugerir a possibilidade de uma relação ameaçadora entre normalistas e sufragistas. Assim, a revista atendia às questões institucionais do discurso favorável a ser divulgado, conforme sua postura e interesses. 
Tendo em vista a discussão da resistência ao poder, perceptível no embate das normalistas e a diretoria da Escola Normal, é matéria de análise a configuração do jogo de forças, onde definitivamente se deve atentar para o movimento que o poder realiza nos indivíduos. Portanto, cabe aqui não uma análise que considere o processo de produção do discurso para as mulheres, nem sua origem, mas uma identificação de sua emergência nas situações ocorridas e nos discursos proferidos.

A pesquisa histórica, com base no que Foucault propõe é "uma prática, é uma luta local e regional, contra as investidas do poder, 'para fazêlo aparecer e feri-lo onde ele é mais invisível e insidioso" (FISCHER, 2007, p. 45). Assim, ao serem apontadas algumas situações do contexto para análise, o mesmo se faz "porque estas configuram o poder em suas extremidades, expõem os rituais, as técnicas, as falas, as mínimas normas, o ordenamento dos indivíduos, enfim, todos os ínfimos elementos da normalização do sujeito" (FISCHER, 2007, p. 50). Desse modo, pode se identificar nas relações, nos jogos de poder e de dominação, os dispositivos de controle e adequação aos efeitos de verdade estabelecidos.

\section{A Primeira Guerra: novas demandas para a atuação feminina}

A proposta neste tópico é delimitar a Guerra como um período de transição para a situação feminina, tanto no que diz respeito à ocupação do espaço público por elas, quanto à nova conformação educacional esperada, devido ao contexto inaugurado. Considera-se que, apesar do Brasil só ter se tornado beligerante em 1917, a Guerra ainda assim tenha repercutido aqui e também tenha trazido essas transformações, vistos os limites tênues de circulação de informações e trocas de experiências devido ao teor do conflito. Leva-se em conta também a grande saída de pessoas da Europa, fugidas do horror da destruição da Guerra, o que causava um trânsito de experiências e desmistificações ainda maior acerca da realidade apresentada pelo conflito, da vulnerabilidade humana nas relações com os governos e também consigo mesmos. 
A dimensão do conflito é apontada por Hobsbawm (1995) na definição do início do "breve" século XX que, segundo ele, foi inaugurado pela I Guerra e conduzido em sua primeira metade, pela extensão com a II Guerra (1939-1945): "Não há como compreender o Breve Século 20 sem ela. Ele foi marcado pela guerra" (HOBSBAWN, 1995, p. 30).

A Careta trazia em destaque a problemática das relações, que numa organização nunca vista antes - um conflito bélico de dimensão global, foi tratada como um novo momento para as mulheres, pela postura que elas tiveram que assumir frente à realidade imposta pela guerra.

Por versar de um tema político, a Guerra também confere às mulheres o silêncio, além de colocá-las num lugar de indiferença quanto à seriedade da conflagração internacional. "Em todos os recantos do planeta em que existem homens cultos, a Grande Guerra em que se debatem as velhas raças européias é o thema preferencial das conversas e a preoccupação absorvente dos espíritos" (CARETA, 19/10/1914, p. 7), os quais não os femininos, segundo a maneira da Careta em tratar a opinião das mulheres.

E assim, é mostrada em charge uma forma de menosprezar a percepção feminina do conflito. "A guerra dentro de casa" (CARETA, 03/10/1914, p. 35) traz a reclamação de uma mulher, ilustrada com um livro segurado displicentemente, quase caindo no chão, e expressão de insatisfação em relação ao pai, que não queria discutir a Guerra, segundo ela, porque não sabia dar uma avaliação a respeito, e prossegue: "Que apotheose horrível! Uma tremenda caudal de sangue alagando vastos campos de trigo pisado!", e como que ignorando a opinião dela, tem como resposta a interrogação sobre qual seria o seu conhecimento sobre os elementos "caudal de sangue" e "vastos campos de trigo", citados em sua fala (CARETA, 03/10/1914, p. 35). Percebe-se no pai a postura comum na Careta em tratar as interferências femininas: a fala da mulher não é avaliada pelo conteúdo, mas grosseiramente pela forma, reduzindo-a ao idiotismo descabido, ainda que a opinião dela tivesse relação com os acontecimentos bélicos.

Mesmo que em concepções e expressões pejorativas sobre o feminino e a sua capacidade de acompanhar as dimensões reais do conflito, 
os rumos que a Guerra dava ao contexto mundial fizeram noticiar na $\mathrm{Ca}$ reta as mudanças desencadeadas: uma situação que aceitaria as mulheres com mais participação social nas relações envolvendo os gêneros.

Ao menos esta era a previsão, ao modo da Careta: "É de crer que com a guerra se abra à mulher um novo mundo com todas as regalias que goza o homem" (CARETA, 24/o8/1918, p. 31, grifo meu). É curioso notar como o texto assume a suposta superioridade masculina de forma naturalizada por meio de discursos diversos como biológicos e sociais, forjados pelas instituições. O jogo de forças que se estabelecia nas relações de gênero afastava o entendimento de que fosse possível a promoção igualitária das experiências humanas. Estaria o argumento para esse entendimento no efeito de verdade causado pela tal costela de Adão, do usual mito da criação do mundo3? Ou na fragilidade física feminina, ou ainda na hipotética debilidade mental sustentada em relação a elas, que as teria tornado inferiores aos homens? 4

Neste ponto, pode-se ainda analisar as relações de gênero em analogia ao movimento da Guerra, em que governantes declararam o conflito para resolver problemas políticos nos campos de batalha, assolando as cidades, devastando multidões que possivelmente não participavam diretamente daquelas ideias. "A morte na guerra é banal" (CARETA, 01/03/1915, p. 16). A morte de milhares ou a limitação das experiências femininas, tudo por instituições que antes de tudo desejavam se sustentar vivas e dominantes, custasse o sangue ou o cerceamento de existências, não importava.

Sobre a questão da ocupação de novos papéis femininos, da nova posição a que as mulheres teriam direito, ela está antes de tudo relacionada à ocupação de cargos antes preenchidos por homens, ao menos na

3 O mito da criação do mundo a que se faz referência encontra-se no Gênesis, o primeiro do conjunto de livros da Bíblia, concebida pela cultura judaico-cristã como escritos inspirados divinamente, portanto dotada de credibilidade para a orientação de seu público seguidor.

$4 \mathrm{O}$ que cabe em relação às perguntas feitas não é o desejo de buscar respostas temporais, mas sim de desconstruir conceitos naturalizados a partir de saberes disseminados nas práticas e discursos institucionais. E o discurso religioso, como a leitura da Bíblia a partir de seu efeito de verdade, parece ter sido um artifício explorado também em outros discursos. 
Europa, nos países que estiveram envolvidos mais diretamente no conflito desde seu início. A Careta trouxe comentários do tipo: "Alguns brasileiros que voltam da Europa salientam em suas impressões o facto de haver em Paris um grande numero de mulheres acephalas" (CARETA, 10/10/1914 p. 36). É importante ressaltar o tipo de conceito sobre o feminino: considerar mulheres acéfalas pela falta da presença maciça dos homens. Dessa vez uma exposição literal de como as mulheres eram colocadas nas relações de gênero, com a dependência delas sob o aspecto do governo masculino.

Há também as notícias de que, nesses lugares, onde os homens estavam em sua maioria nos campos de batalha, as mulheres assumiam seus postos. Em 1917, a Careta ainda ressaltou um possível problema ao fim da Guerra, que apesar da garantia de que os combatentes, quando voltassem da Guerra, teriam seus trabalhos mantidos, os direitos deles acabariam "burlados pela preferência ao sapiente labor feminino em todas as situações em que a habilidade das mulheres houver demonstrado superioridade sobre o hábil trabalho do homem" (CARETA, 15/o9/1917, p. 8). Até mesmo fotos sobre essa situação do trabalho feminino a Careta publicou, como é o caso dos bonds de Paris, cuja legenda anunciava que "as mulheres substituem as funcções dos conductores e cobradores dos bonds" (CARETA, 20/03/1915, p. 34).

É necessário ressaltar sobre a educação oferecida às mulheres, a perspectiva de que uma nova demanda educacional tendia a surgir desse novo quadro.

Para tal, leva-se em conta que a crescente tecnologia em avanço, e pode-se mesmo afirmar acelerada pela Guerra, exigiria pessoas capacitadas para o mundo do trabalho. Como o que interessa aos empregadores é desde sempre a habilidade do trabalhador, elas poderiam começar a concorrer, com o passar do tempo, a cargos cada vez mais elaborados e, para tal, ainda mais a escolarização e aquisição de habilidades antes dispensadas, seriam fatores determinantes.

A partir dessa esfera, portanto, admite-se uma nova realidade para as mulheres do ponto de vista educacional, com vistas a uma colocação 
tão conscientes de suas possibilidades e participação no contexto como não pudera ter acontecido até aquele momento.

\section{Considerações}

O que se considera de maior importância para esta pesquisa, tanto pelo campo de estudos que integra - o da história da educação, - quanto pelo teor social que impõe, é a determinação de que a educação favorece a vida, e no aspecto feminino, incorporada à resistência, pode-se dizer responsável pela tomada de um lugar social que deveria desde sempre, pressupor uma igualdade de condições para atuação. Se não o foi no recorte temporal aqui abordado, é porque fazia parte dos jogos de força que tentavam limitar e desfavorecer as mulheres, sem, no entanto, impedir a possibilidade de vir a ser.

\section{Referências}

ALBUQUERQUE JR., D. M. História: A arte de inventar o passado. Ensaios de teoria da história. Bauru: Edusc, 2007.

ALMEIDA, M. M. Na trilha de um andarengo: Alcides Maya (18771944). Porto Alegre: EDIPUCRS, 1994.

CARVALHO, J. M. Os bestializados: o Rio de Janeiro e a República que não foi. São Paulo: Companhia das Letras, 1987.

DELEUZE, G. Foucault. São Paulo: Editora Brasiliense, 1988.

D'INCAO, M. Â. Mulher e família burguesa. In: PRIORI, M. História das mulheres no Brasil. (org.). São Paulo: Contexto, 1997.

FISCHER, R. M. B. A paixão em trabalhar com Foucault. In: COSTA, M. V. (org.). Caminhos investigativos I: Novos olhares na pesquisa em educação. $3^{\text {a }}$ ed. Rio de Janeiro: Lamparina Editora: 2007.

FOUCAULT, M. História da sexualidade I: A vontade de saber. Rio de Janeiro: Edições Graal, 1988. 
. Em defesa da sociedade: Curso no Collège de France (19751976). São Paulo: Martins Fontes, 2005. . A ordem do discurso. $20^{\text {a }}$ Ed. São Paulo: Edições Loyola, $2010 a$. 2010b. . Vigiar e punir: Nascimento da prisão. $38^{\mathrm{a}}$ ed. Petrópolis: Vozes,

HOBSBAWN, E. Era dos extremos: o breve século XX (1914-1991). São Paulo, Companhia das Letras, 1995.

SEVCENKO, N. A capital irradiante: técnica, ritmos e ritos do Rio. In: SEVCENKO, N. (org.). História da vida privada no Brasil 3: República: da Belle Époque à era do rádio. São Paulo: Companhia das Letras, 2006.

\section{Fontes}

A GAZETA, São Paulo, 14/o6/1915 a 16/06/1915.

CARETA, Rio de Janeiro. Editora Kosmos, 1914 a 1918.

Recebido em 22 de abril de 2017. Aprovado em 12 de julho de 2017. 